\title{
Developing standard size chart for males (18-26 years) through anthropometric survey
}

\author{
Archana Bahuguna and Alka Goel
}

Received: 15.08.2020; Revised: 18.10.2020; Accepted: 01.11 .2020

See end of the paper for authors' affiliations

Archana Bahuguna Department of Clothing and

Textiles, College of Home Science, G.B. Pant University of Agriculture and Technology, Pantnagar, U.S. Nagar (Uttarakhand) India

Email : archana5337bahuguna@ gmail.com
ABSTRACT : The aim of this study is to establish anthropometric data for Khadi industries of Uttarakhand in order to promote Khadi stitched garments amongst male youth. Data were collected from all of the geographical regions of Uttarakhand i.e., High hills ( $>2500 \mathrm{~m}$. altitude), Middle hills (1000-2500 m. altitude) and foothills or plains ( $<1000 \mathrm{~m}$. altitude). Totally, about 1080 measurements of male students (18-26 years) were collected. Data purging process has been carried out before using it for developing standards. Data collected were analysed using percentile base for the $5^{\text {th }}, 50^{\text {th }}$, and $95^{\text {th }}$ percentile. Based on the percentile, standard size chart was developed. Visible difference has been observed on standards when compared with USA and Italy standards for the same measurements. This proved that further studies should be conducted for other age groups not only in the male but also in the female category.

KEY WORDS: Males, Anthropometric data, Khadi industries, Garments

- HOW TO CITE THIS PAPER : Bahuguna, Archana and Goel, Alka (2020). Developing standard size chart for males (18-26 years) through anthropometric survey. Asian J. Home Sci., 15 (2) : 242-246, DOI: 10.15740/HAS/AJHS/15.2/242-246. Copyright@ 2020: Hind Agri-Horticultural Society. 